\title{
Effects of Water Yam and Corn Starches on the Interacting Variables Influencing the Disintegration of Chloroquine Phosphate Tablets
}

\author{
Adenike Okunlola and Oluwatoyin A. Odeku \\ Department of Pharmaceutics and Industrial Pharmacy, University of Ibadan, Ibadan, Nigeria
}

\begin{abstract}
The individual and effects of interaction of nature $(\mathrm{X})$ and concentration $(\mathrm{Y})$ of disintegrant and the relative density $(\mathrm{Z})$ on the mechanical and release properties of chloroquine phosphate tablets were studied using a $2^{3}$ factorial experimental design. Water yam starch ("low" level) and corn starch ("high" level) were used as disintegrants at concentrations of $5.0 \%$ and $20.0 \% \mathrm{w} / \mathrm{w}$. The mechanical properties were assessed using the crushing strength (CS) and friability (F) and the release properties by the disintegration time (DT) and dissolution time $\left(\mathrm{t}_{80}\right)$. Increasing the concentration of disintegrants and the relative density of tablets resulted in increase in CS, but decrease in F, DT and $t_{80}$. The ranking of the individual coefficient values was $Z>X>Y$ for $C S, Z>X>Y$ for $F$ and DT, and $\mathrm{Y}>\mathrm{X}>\mathrm{Z}$ for $\mathrm{t}_{80}$ while that for the interaction coefficient was $\mathrm{X}-\mathrm{Z}>\mathrm{Y}-\mathrm{Z}>\mathrm{X}-\mathrm{Y}$ for $\mathrm{CS}, \mathrm{Y}-\mathrm{Z}>\mathrm{X}-\mathrm{Z}>\mathrm{X}-\mathrm{Y}$ for $\mathrm{F}, \mathrm{Y}-\mathrm{Z}>$ $\mathrm{X}-\mathrm{Y}>\mathrm{X}-\mathrm{Z}$ for DT and $\mathrm{t}_{80}$. Changing the disintegrant from corn starch to water yam starch resulted in decrease in CS, DT and $t_{80}$ but increase in $F$. The results showed considerable interaction between the variables employed and suggested that water yam could be an alternative disintegrant to corn starch particularly where faster disintegration and release are required.
\end{abstract}

Keywords: Starch, disintegrant, water yam, mechanical properties, chloroquine phosphate

\section{INTRODUCTION}

Disintegrants are agents added to tablet formulations to promote the breakup of the tablet into smaller fragments in an aqueous environment thereby increasing the available surface area and promoting a more rapid release of the drug substance. Disintegration has been viewed as the net balance of the interaction between the adhesive and disintegration forces. ${ }^{1}$ Thus disintegrants have the major function of opposing the effect of the tablet binder and the physical forces that act on the formulation granules under compression to form a tablet. Ideally, disintegrants should cause the tablet to

Correspondence to: Oluwatoyin A. Odeku

E. mail: pejuodeku@yahoo.com;

oa.odeku@mail.ui.edu.ng

Dhaka Univ. J. Pharm. Sci. 10(1): 21-28, 2011 (June) disrupt, not only into the granules from which it was compressed, but also into powder particles from which the granulation was prepared. ${ }^{2}$

There are three major mechanisms of tablet disintegration: swelling, porosity and capillary action (Wicking) and deformation. ${ }^{3}$ Although not all effective disintegrants swell when in contact with water, swelling is believed to be a mechanism in which certain disintegrants such as starch impart their effect. By swelling, the adhesiveness of other ingredients in a tablet is overcome causing the tablet to fall apart. Effective disintegrants that do not swell are believed to impart their disintegrating action through porosity and capillary action. Tablet porosity provides pathways for the penetration of fluid into tablets. The disintegrant particles themselves act to enhance porosity and provide these pathways into the 
tablet. Liquid is drawn up or "wicked" into these pathways through capillary action leading to rupturing of the interparticulate bonds, causing the tablet to break apart. ${ }^{1}$ It is believed that no single mechanism is responsible for the action of most disintegrants. But rather, it is more likely the result of inter-relationships between these major mechanisms.

The classical example of the earliest known disintegrant is starch. Corn starch was recognized as being the ingredient in tablet formulations responsible for disintegration as early as $1906 .{ }^{4}$ Effort has been made in recent times to develop starches from locally available plant species with a view to discovering starches from botanical sources different from the official ones. Dioscorea alata L is the most extensively cultivated species of yam in the West Indies, the pacific Islands and tropical Asia and its production is second to that of Dioscorea rotundata in West Africa. ${ }^{5}$ Like other tropical yam tubers with high starch content (about $50-80 \% \mathrm{w} / \mathrm{w}$ ), ${ }^{6}$ Dioscorea alata is a potential source of starch that is yet to be explored commercially. ${ }^{7}$ Studies on the material and tablet properties of water yam starch have shown that the physicochemical and material properties varied considerably from official corn starch. Water yam starch was observed to be compressible, forming tablets of acceptable crushing force. ${ }^{8}$ The compactibility of the starch appeared to be related to the particle size $(25.3 \mu \mathrm{m})$, shape (oval) and amylose content $(27.33 \%)$ of the starch. ${ }^{9}$ In another study, the suitability and relative efficiency of water yam starch as disintegrant was investigated in comparison to official corn starch. ${ }^{9}$ Water yam starch showed faster disintegration and release properties than corn starch when used as intragranular disintegrant in chloroquine phosphate tablets.

However, the quantitative effects of important formulation and processing variables on the release properties of the tablets containing water yam starch as disintegrant appears to be largely unexplored. The factorial experimental design has been found useful in the analysis of the quantitative individual and effects of interaction of various formulation factors on the mechanical strength, disintegration and dissolution rate of various tablets. Chloroquine phosphate USP, a 4-aminoquinoline compound, is an antimalarial and amoebicidal drug. Chloroquine phosphate is only slightly soluble in water and disintegration would play a significant role in the dissolution process of the tablets. It therefore requires a disintegrant, among other excipients, to release the drug in a predictable manner. ${ }^{10-13}$ Thus, in the present study, efforts have been made to the relative quantitative effects of nature of starch disintegrant, concentration of disintegrant and the relative density of the tablets on the mechanical and release properties of chloroquine phosphate tablets using a factorial experimental design. ${ }^{10}$

\section{MATERIALS AND METHODS}

The materials used were chloroquine phosphate BP and corn starch BP (BDH Chemicals Ltd., Poole, U.K.), polyvinyl pyrrolidone, PVP mol.wt. 44,000 (BDH Chemicals Ltd., Poole, U.K.) and tubers of Dioscorea alata (Water yam) obtained from local farmers in Ibadan, Nigeria and authenticated. The starch was extracted from the tubers using established procedures. $^{14}$

Preparation of granules. Batches (200 g) of formulation containing chloroquine phosphate and the starch as disintegrant at different concentrations of $5-20 \% \mathrm{w} / \mathrm{w}$ were dry mixed and then moistened with $2 \% \mathrm{w} / \mathrm{w}$ PVP solution as binder. Massing was continued for 5 minutes and the wet masses were granulated by passing them manually through a mesh 12 sieve $(1400 \mu \mathrm{m})$. These were dried in a hot air oven at $50^{\circ} \mathrm{C}$ for 18 hours. Dried granules were sieved through a mesh 16 sieve $(1000 \mu \mathrm{m})$ and then stored in air tight container. The moisture content of the granules was determined and found to be between $2-4 \% \mathrm{w} / \mathrm{w}$. Particle densities were determined by the pycnometer method, using xylene as the displacement fluid. ${ }^{15}$

Preparation of tablets. Quantities $(500 \mathrm{mg})$ of granules within the size range of $710-1000 \mu \mathrm{m}$ were compressed for 30 seconds into tablets with predetermined loads on a Carver hydraulic press (Model C, Carver Inc. Menomonee Falls, Wisconsin, 
U.S.A.) using a $10.5 \mathrm{~mm}$ die and flat-faced punches lubricated with a $1 \%$ dispersion of magnesium stearate in acetone before each compression. After ejection, the tablets were stored over silica gel for 24 hours to allow for elastic recovery and hardening. The weights $(\mathrm{w})$ and dimensions of the tablets were then determined to within $\pm 1 \mathrm{mg}$ and $0.01 \mathrm{~mm}$ respectively, and their relative densities, $Z$, were calculated using the equation:

$\mathrm{Z}=\mathrm{w} / \mathrm{V}_{\mathrm{t}} \cdot \rho_{\mathrm{s}}$

where $V_{t}$ is the volume, $\mathrm{cm}^{3}$, of the tablet including the hole when present and $\rho_{\mathrm{s}}$ is the particle density, $\mathrm{gcm}^{-3}$, of the solid material.

Determination of crushing strength. The crushing strength of the chloroquine phosphate tablets (T) was determined at room temperature by diametral compression ${ }^{16}$ using a hardness tester (Ketan Scientific \& Chemicals, Ahmedebad, India). Results were taken only from tablets which split cleanly into two halves without any sign of lamination. All measurements were made in quadruplicates and the results given are the mean of several determinations.

Determination of friability. The percent friability of the tablets was determined using a friabilator (Veego Scientific devices, Mumbai, Maharashtra, India) operated at $25 \mathrm{rpm}$ for 4 minutes. Determinations were made in quadruplicates.

Disintegration test. The disintegration time of on the tablets was determined in distilled water at $37 \pm 0.5^{\circ} \mathrm{C}$ using a disintegration tester (Veego Scientific devices, Mumbai, Maharashtra, India). Determinations were done in quadruplicates.

Dissolution test. Dissolution test was carried out with the tablets using the USPXX III basket method (Hanson Model 72RL, U.S.A) rotated at $100 \mathrm{rpm}$ in $900 \mathrm{ml}$ of $0.1 \mathrm{M} \mathrm{HCL}$, maintained at $37 \pm 0.5^{\circ} \mathrm{C}$. Samples $(5 \mathrm{ml})$ were withdrawn and replaced with equal volume of fresh medium. The sample was diluted and the amount of chloroquine phosphate released was determined at wavelength of $255 \mathrm{~nm}$, using a UV/Visible spectrophotometer (Phillips Pye Unicam, PU 8610 Kinetics, Sarose scientific instruments, Cambridge, U.K.). Determinations were done in triplicates.
Experimental design. To study the effect of the nature of starch disintegrant $(X)$, concentration of disintegrant $(\mathrm{Y})$ and relative density of the tablet $(\mathrm{Z})$ on crushing strength, friability, disintegration time and dissolution time of the tablets, the experiments were performed in a factorial design which involved the use of simple statistics. The basis of the experiment was that each of the three variables was utilized at low (1) and high (2) levels. The number of experiments in the design was $2^{3}$ i.e. 8 . Using the above nomenclature, the various combinations between the variables used in the design were:

$$
\begin{array}{llll}
X_{1} Y_{1} Z_{1}, & X_{1} Y_{1} Z_{2}, & X_{1} Y_{2} Z_{1}, & X_{1} Y_{2} Z_{2} \\
X_{2} Y_{2} Z_{2}, & X_{2} Y_{2} Z_{1}, & X_{2} Y_{1} Z_{2}, & X_{2} Y_{1} Z_{1}
\end{array}
$$

$X_{1}=$ Nature of disintegrant (water yam starch)

$\mathrm{X}_{2}=$ Nature of disintegrant (corn starch)

$\mathrm{Y}_{1}=$ Concentration of disintegrant $(5 \%)$

$\mathrm{Y}_{2}=$ Concentration of disintegrant $(20 \%)$

$Z_{1}=$ Relative density of 0.80

$Z_{2}=$ Relative density of 0.90

The effects of increasing $X$ from low level to its high level on the crushing strength, friability, disintegration and dissolution time were found by summing all crushing strength (or friability, disintegration and dissolution time) results of samples containing "high" level of $\mathrm{X}$ and subtracting the sum of the results of samples containing "low" levels of $\mathrm{X}$. That is:

$1 / 4\left[\left(X_{2} Y_{2} Z_{2}+X_{2} Y_{1} Z_{2}+X_{2} Y_{2} Z_{1}+X_{2} Y_{1} Z_{1}\right)-\left(X_{1} Y_{1}\right.\right.$ $\left.\mathrm{Z}_{1}+\mathrm{X}_{1} \mathrm{Y}_{2} \mathrm{Z}_{1}+\mathrm{X}_{1} \mathrm{Y}_{1} \mathrm{Z}_{2}+\mathrm{X}_{1} \mathrm{Y}_{2} \mathrm{Z}_{2}\right)$

A quantitative measurement of the effect of $X$ on crushing strength (or friability, disintegration and dissolution time) of the tablet would be the amount by which the result of this treatment departed by zero, irrespective of whether positive or negative. Similar expressions were used for finding the effects of $\mathrm{Y}$ and $\mathrm{Z}$.

To determine whether there was any interaction between two variables, the result of the combinations in which they appear together at either "high" or "low" levels were summed and the sum of other combinations subtracted from this to obtain the interaction coefficient. 
For $\mathrm{X}$ and $\mathrm{Y}: 1 / 4\left[\left(\mathrm{X}_{2} \mathrm{Y}_{2} \mathrm{Z}_{1}+\mathrm{X}_{2} \mathrm{Y}_{2} \mathrm{Z}_{2}+\mathrm{X}_{1} \mathrm{Y}_{1} \mathrm{Z}_{2}\right.\right.$ $\left.\left.+X_{1} Y_{1} Z_{1}\right)-\left(X_{2} Y_{1} Z_{2}+X_{2} Y_{1} Z_{1}+X_{1} Y_{2} Z_{1}+X_{1} Y_{2} Z_{2}\right)\right]$

A result of zero indicates no interaction, but if the interaction coefficient is significantly removed from zero, it can be concluded that the two variables concerned are interacting with each other. The extent of deviation from zero is a measure of interaction. Similar expressions were used for estimating the interaction between $\mathrm{X}$ and $\mathrm{Z}$, and between $\mathrm{Y}$ and $\mathrm{Z}$.

Statistical analysis. Statistical analysis was carried out by using the analysis of variance (ANOVA) and Tukey-Kramer multiple comparison tests on a computer software GraphPad Prism 4 (GraphPad Software Inc. San Diego, USA).

\section{RESULTS}

The values of crushing strength (CS), friability (F), disintegration time (DT) and dissolution time $\left(t_{80}\right)$ at two selected relative densities of 0.8 and 0.9 (representative of the range of relative density normally achieved for commercial chloroquine phosphate tablets) for the factorial experiments are given in Table 1. These values were used to calculate the individual and interaction coefficients for the variables, presented in Table 2 . The values indicate the quantitative effects of the three variables studied on the mechanical and release properties of chloroquine phosphate tablets. In comparing the formulations, the ranking of the individual (independent) coefficient values for the formulations was $Z>X>Y$ for CS, $F$ and DT and $Y>X>Z$ for $t_{80}$. The ranking of the interaction effects on CS was $X$ $\mathrm{Z}>\mathrm{Y}-\mathrm{Z}>\mathrm{X}-\mathrm{Y}$, on $\mathrm{F}$ was $\mathrm{Y}-\mathrm{Z}>\mathrm{X}-\mathrm{Z}>\mathrm{X}-\mathrm{Y}$, on DT and $t_{80}$ was $Y-Z>X-Y>X-Z$. Representative plots of $\mathrm{CS}, \mathrm{F}$ and DT versus relative density for chloroquine phosphate tablets containing $20 \% \mathrm{w} / \mathrm{w}$ of the disintegrants are presented in Figures 1, 2 and 3 respectively. The plots of percentage drug released versus time at relative density of 0.8 for the chloroquine phosphate tablets containing $20 \% \mathrm{w} / \mathrm{w}$ of the disintegrants are presented in Figure 4.

Table 1. Crushing strength (CS), friability (F), disintegration time (DT) and dissolution time ( $\mathrm{t}_{80}$ ) of chloroquine phosphate tablets for factorial experimental design

\begin{tabular}{ccccc}
\hline $\begin{array}{c}\text { Variables and } \\
\text { combination codes }\end{array}$ & $\begin{array}{c}\text { Crushing strength } \\
(\mathrm{N})\end{array}$ & $\begin{array}{c}\text { Friability } \\
(\%)\end{array}$ & Disintegration time (min) & $\begin{array}{c}\mathrm{t}_{80} \\
(\mathrm{~min})\end{array}$ \\
\hline $\mathrm{X}_{1} \mathrm{Y}_{1} \mathrm{Z}_{1}$ & 48.20 & 3.30 & 7.50 & 30.00 \\
$\mathrm{X}_{1} \mathrm{Y}_{1} \mathrm{Z}_{2}$ & 72.00 & 2.25 & 8.79 & 37.50 \\
$\mathrm{X}_{1} \mathrm{Y}_{2} \mathrm{Z}_{1}$ & 51.50 & 2.75 & 6.50 & 24.00 \\
$\mathrm{X}_{1} \mathrm{Y}_{2} \mathrm{Z}_{2}$ & 94.00 & 1.93 & 7.42 & 27.25 \\
$\mathrm{X}_{2} \mathrm{Y}_{1} \mathrm{Z}_{1}$ & 55.20 & 2.75 & 7.25 & 35.00 \\
$\mathrm{X}_{2} \mathrm{Y}_{1} \mathrm{Z}_{2}$ & 100.00 & 1.50 & 10.20 & 42.50 \\
$\mathrm{X}_{2} \mathrm{Y}_{2} \mathrm{Z}_{1}$ & 75.00 & 1.51 & 8.10 & 30.00 \\
$\mathrm{X}_{2} \mathrm{Y}_{2} \mathrm{Z}_{2}$ & 116.33 & 1.39 & 9.05 & 32.50 \\
\hline
\end{tabular}

Table 2. Individual effects of relative density (D), concentration of disintegrant (C), nature of disintegrant (N) on the crushing strength, friability, disintegration and dissolution time of chloroquine phosphate tablets.

\begin{tabular}{ccccc}
\hline Variables & $\begin{array}{c}\text { Crushing strength } \\
(\mathrm{N})\end{array}$ & $\begin{array}{c}\text { Friability } \\
(\%)\end{array}$ & Disintegration time $(\mathrm{min})$ & $\begin{array}{c}\mathrm{t}_{80} \\
(\mathrm{~min})\end{array}$ \\
\hline Independent coefficient & & & & 5.31 \\
$\mathrm{X}$ & 20.21 & -0.77 & 1.10 & -7.81 \\
$\mathrm{Y}$ & 15.36 & -0.56 & -0.67 & 5.19 \\
$\mathrm{Z}$ & 38.11 & -0.81 & 1.53 & $\mathrm{p}<0.001$ \\
$\mathrm{p}$ & $\mathrm{p}<0.001$ & $\mathrm{p}<0.001$ & & 0.31 \\
Interaction coefficient & & & 0.52 & -0.19 \\
$\mathrm{X}-\mathrm{Y}$ & 2.71 & -0.12 & 0.42 & -2.31 \\
$\mathrm{X}-\mathrm{Z}$ & 4.96 & 0.13 & -0.59 & $\mathrm{p}<0.001$ \\
$\mathrm{Y}-\mathrm{Z}$ & 3.81 & 0.34 & $\mathrm{p}<0.001$ & $\mathrm{p}$ \\
$\mathrm{p}$ & $\mathrm{p}<0.001$ & $\mathrm{p}<0.001$ & & \\
\hline
\end{tabular}




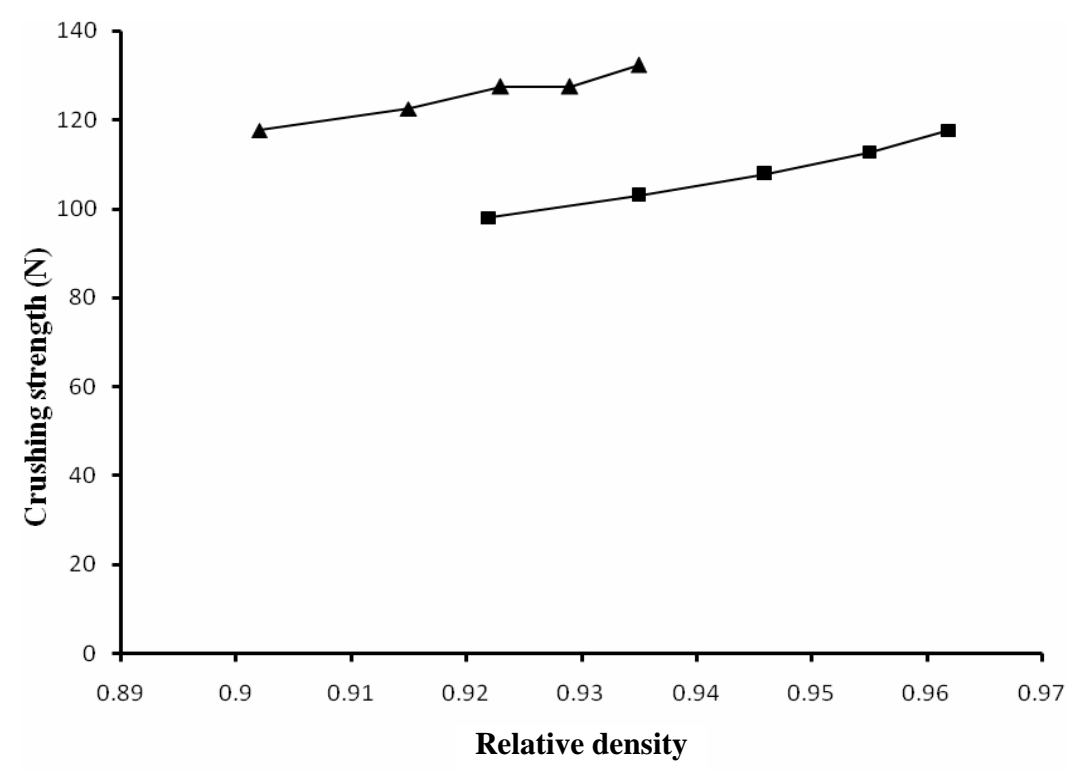

Figure 1. Plot of crushing strength versus relative density for chloroquine phosphate tablets containing $20 \% \mathrm{w} / \mathrm{w}$ of disintegrant: $\mathbf{m}$, water yam starch and $\boldsymbol{\Lambda}$, corn starch.

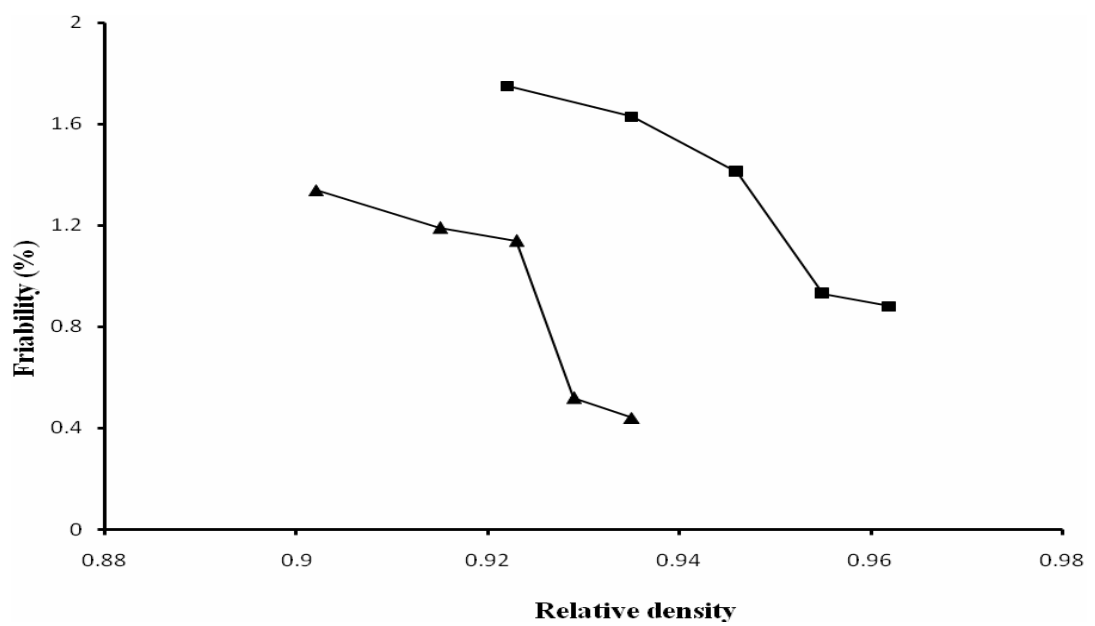

Figure 2. Plot of friability versus relative density for chloroquine phosphate tablets containing $20 \% \mathrm{w} / \mathrm{w}$ of disintegrant: $\boldsymbol{m}$, water yam starch and $\boldsymbol{\Lambda}$, corn starch.

\section{DISCUSSION}

The influence of $\mathrm{X}$ on $\mathrm{CS}$, DT and $\mathrm{t}_{80}$ was positive indicating that water yam starch, which represented the "low" level, produced tablets with lower mechanical strength and shorter disintegration and dissolution time than the tablets containing corn starch. On the other hand, the influence of $\mathrm{X}$ on $\mathrm{F}$ was negative; indicating that tablets containing corn starch which represents the "high" level of X had lower friability. Thus, water yam starch would appear to be a more useful disintegrant than corn starch since it produced tablets of acceptable crushing strength ( $>$ B.P specification of $4 \mathrm{KgF}$ ) with faster disintegration and dissolution times.

The effect of $\mathrm{Y}$ was positive on CS but was negative on $F$, DT and $t_{80}$. This indicates that increasing the concentration of disintegrant from 5\% to $20 \% \mathrm{w} / \mathrm{w}$ led to an increase in the crushing 
strength but a decrease in friability, disintegration and dissolution times of the tablets. Starch is inherently more plastic than chloroquine phosphate powder and an increase in the concentration of the starch added internally as endodisintegrant is likely to increase the plasticity, compressibility and consolidation tendency of the tablets. The availability of more contact points between particles as the disintegrant concentration increase results in the formation of solid bonds which may lead to the formation of tablets with higher CS and therefore lower $\mathrm{F}^{17}{ }^{17}$ On the other hand, tablet disintegration and dissolution times generally decreased with increase in disintegrant concentration. This could be due to the fact that the higher the amount of starch disintegrant exposed to the disintegrating fluid, the higher the amount of water absorbed and subsequent generation of higher swelling force to facilitate disintegration. ${ }^{1}$ This clearly shows the importance of carefully selecting the concentration of the disintegrant in order to obtain tablets with adequate balance between mechanical strength and release properties.

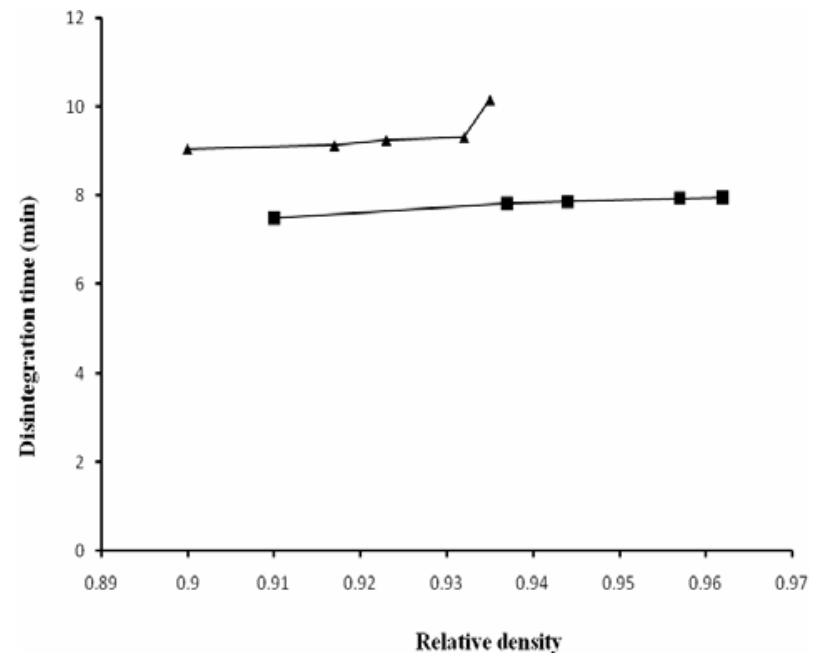

Figure 3. Plot of disintegration time versus relative density for chloroquine phosphate tablets containing $20 \% \mathrm{w} / \mathrm{w}$ of disintegrant: a, water yam starch and $\boldsymbol{\Lambda}$, corn starch.

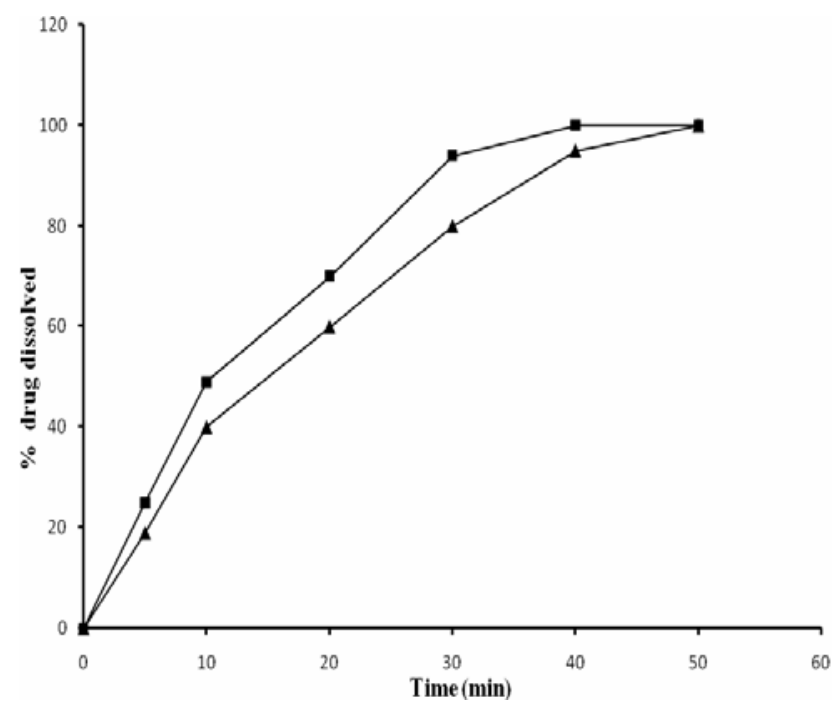

Figure 4. Dissolution profile of chloroquine phosphate tablets containing $20 \% \mathrm{w} / \mathrm{w}$ of starches as disintegrant at relative density of 0.80 : $\mathbf{m}$, water yam starch; $\boldsymbol{\Delta}$, Corn starch. 
Increasing the relative density from 0.80 to 0.90 led to an increase in CS, DT and $t_{80}$, but a decrease in F. Relative density $(Z)$ had the highest effect on crushing strength and on dissolution time. This is expected as the relative density of a pharmaceutical material increases with increase in compression pressure. With increase in compression pressure, there is decrease in porosity or reduction in capillary microstructure of the tablets ${ }^{15}$ resulting in closer packing. Thus, more solid bonds will be formed between the particles leading to an increase in the mechanical strength of the tablets. Particle rearrangement, fragmentation and deformation may also result in the closure of the inter- and intragranular pore spaces, thereby reducing the capillary microstructure of tablets. The reduction in the size of the capillary spaces between the particles will reduce the rate of penetration of water, in turn leading to an increase in disintegration and dissolution times. There was significant difference in the effects of X, Y and Z on CS and DT $(\mathrm{p}<0.01)$ as compared to their effects on the other properties of chloroquine phosphate tablets.

The interaction coefficient values indicate that all the variables interacted with each other to alter the mechanical and release properties of the tablets. Combinations $\mathrm{X}-\mathrm{Y}, \mathrm{X}-\mathrm{Z}$ and $\mathrm{Y}-\mathrm{Z}$ had the largest interaction effect on CS but the least effect on $F$. Relative density $(Z)$ appears to interact with all the variables. This is expected as $\mathrm{Z}$ had the largest individual effects on mechanical and disintegration properties of the tablets. In general, the magnitude of the interaction effects shows that there were statistically significant $(\mathrm{p}<0.001) \quad$ interactions between $\mathrm{Z}$ and the other variables, $\mathrm{X}$ and $\mathrm{Y}$.

The effect of concentration (Y) on tablet properties have been shown to be strongly related to the nature of the disintegrant $(Z)$ and the relative density of the tablet (Z) employed in the formulation. ${ }^{15}$ The results obtained suggest that changing the type of disintegrant from water yam starch to corn starch would lead to an increase in crushing strength, disintegration and dissolution times but an decrease in friability of chloroquine phosphate tablets. Water yam starch may therefore be regarded as a better disintegrant which provides faster disintegration and dissolution of tablets. The results also show that increasing the disintegrant concentration (Y) of the tablets would lead to an increase in crushing strength, disintegration and dissolution times but a decrease in friability of chloroquine phosphate tablets. Thus, care should be taken in choosing the type and concentration of disintegrant employed in a formulation. This is to enable the production of tablets with the adequate balance between mechanical and drug release properties.

\section{CONCLUSION}

The results show that there was considerable interaction between the variables for the different disintegrants as evidenced by the magnitude of the individual and interaction coefficients employed on the crushing strength, friability, disintegration and dissolution times of chloroquine phosphate tablets. Thus, water yam starch can be useful as a disintegrant in tablet formulations that require fast release properties and this study can be useful in developing tablet formulations for other drugs.

\section{REFERENCES}

1. Wan, L.S.C. and Prasad, K.P.P. 1989. Uptake of water into tablets with low substitute carboxymethyl cellulose sodium as disintegrant. Intl. J. Pharmaceut.55, 115-121.

2. Bi, Y., Yonezawa, Y and Sunada, H. 1999. Rapidly Disintegrating Tablets Prepared by the Wet Compression Method: Mechanism and Optimization. J. Pharmaceutical Sci. 88, 1004-1010.

3. Luangtanan-Anan, $\mathrm{M}$ and Fell, J.T. 1990. Bonding mechanisms in tableting. Intl. J. Pharmaceut. 60, 197-202.

4. Carter, J.C. 2002. The role of disintegrants in solid oral dosage manufacture. Carter Pharmaceuticals Consulting Inc.

5. Agwunobi, L.N. 1999. Dioscorea alata (Water yam) as a replacement for maize I diet for laying hens. Tropical Animal Health and Production 31, 391-396.

6. Gebre-Mariam, T. and Schimdt, P.C. 1998. Some physicochemical properties of Dioscorea starch from Ethiopia. Starch/Stärke 50, 241-246.

7. Farhat, I.A., Oguntona, T. and Neale, R.J. 1999. Characterization of starches from West African yams. J. Sci. Food and Agric. 79, 2105-211. 
8. Odeku, O.A. and Picker-Freyer, K.M. 2007. Analysis of the material and tablet formation properties of four Dioscorea starches. Starch/Stärke 59, 430-444.

9. A. Okunlola and O.A Odeku. 2008. Comparative evaluation of starches obtained from Dioscorea species as intragranular tablet disintegrant. J. Drug Deliv. Sci. Technol. 18, 445-4.

10. Woolfall, R.C. 1964. An approach to product formulation. Soap Perfume Cosmetic 37, 965-970.

11. Odeku, O.A. 2008. Effects of albizia gum and gelatin on interacting variables affecting the mechanical and release properties of paracetamol tablets. J. Drug Deliv. Sci. Technol. 18, 215-217.

12. Odeku, O.A. and Itiola, O.A. 2003. Effects of interacting variables on the tensile strength and the release properties of paracetamol tablets. Trop. J. Pharm. Res. 2, 147-153.
13. Okunlola, A. and Odeku, O.A. 2009. Formulation factors affecting the binding properties of Chinese yam (Dioscorea oppositifolia) and corn starches. Asian Pac. J. Trop. Med. 2, 1-7.

14. Radley, J. 1976. Starch Production Technology. ASP, London. pp. 189-229.

15. Itiola, O.A. and Pilpel, O.A. 1986. Tableting characteristics of metronidazole formulations. Intl. J. Pharmaceutics 31, 99105.

16. Fell, J.T. and Newton, M.J. 1970. Determination of tablet strength by diametral compression test. J. Pharmaceutical Sci. 59, 688-691.

17. Pilpel N. Otuyemi, S.O. and Kurup, T.R.R. 1978. Factors affecting the disintegration and dissolution of chloroquine phosphate/starch tablets. J. Pharm. Pharmacol. 30, 214-219. 